\title{
How Similar are the Determinants of Mortality and Fertility?*
}

\author{
Syed Mubashir Ali, Hussain BaKhsh SiYal and Mehboob Sultan
}

\section{INTRODUCTION}

In a pre-transition situation both fertility and mortality are high. However, in the process of demographic transition, fertility decline follows mortality decline and when the demographic transition is complete both these variables vary closely at a low level. In other words, both these variables behave in a way which are complimentary to each other and hence it may be hypothesised that the factors which explain variation in fertility should explain variation in mortality or vice versa.

Nevertheless, the strength and sometimes even direction of these determinants may vary from time to time and from place to place. Presently, Pakistan is in the process of demographic transition. By using the 1990-91 Pakistan Demographic and Health Survey data, here in this exercise, an attempt is made to identify and investigate the similarities and the differences if any, in the determinants of both fertility and mortality.

\section{METHODOLOGY AND VARIABLES}

The technique of Multiple Regression analysis is used to test the statistical significance of the effects of each independent variable on the dependent variable. The two dependent variables are: (i) Children Ever Born (CEB) and (ii) Children Dead.

The independent variables include, age, age at marriage, and the work status of women since marriage is used as a dummy variable. The durables in the household are considered as a proxy for economic status. There are 10 durables listed in the questionnaire, possession of which are asked one by one. Each durable is assigned a certain score. A zero score is assigned to the nonpossession of any durable by the household. The scores, when added together, will yield the economic status of a housēhold. received.

*Owing to unavoidable circumstances, the discussant's comments on this paper have not been

Syed Mubashir Ali and Hussain Bakhsh Siyal are Research Demographers at the Pakistan Institute of Development Economics, Islamabad and Mehboob Sultan is Research Fellow at the National Institute of Population Studies, Islamabad. 
Wife's and husband's education is included as two binary variables where 'Edu1' are all those who have studied upto primary and 'Edu2' who have studied beyond primary. For both these categories, all those who have not studied in the school were the reference category. Likewise, breastfeeding in Table 1 is categorised in such a way that the average duration of breastfeeding, ranging between 6 to 12 months, is 'Breastfed 1' and 13 months or longer is 'Breastfed2'. All those who have never breastfed and where mean duration of breastfeeding is less than six months is the reference category.

Husband's education is included in the regression equations mainly because it is presumed to have an effect on decision-making in the male dominated Pakistani society. Here most of the decisions particularly those of vital importance such as the choice and number of children, immunisation of the children or taking the sick children to a doctor are mainly the responsibility of a male member or a husband. A change in the attitudes of males by providing them with further education may facilitate the demographic transition to progress at a faster pace than otherwise expected.

In order to determine the effect of sex preference on the two dependent variables, the proportion of female children in the total is taken as an index of sex preference. The place of residence in terms of urban and rural areas-where ' $l$ ' is assigned to urban and ' 0 ' to rural residents-has been introduced in the regression equations in order to determine the effect of urbanisation on the above two stated dependent variables. 'Age' and 'age at marriage' are taken at interval scale whereas 'ever users' and 'immunisation' are introduced in the equations as dummy variables.

\section{REGRESSION RESULTS}

Regression results pertaining to two dependent variables ('Children Ever Born' and 'Children Dead') are presented in Tables 1 and 2. Each table represents four equations. The first equation pertains to all women who have at least one child in the 5 years preceding the survey and the other three equations are a breakdown of mothers by age groups.

Overall, the results are encouraging and the explanatory variables bear the expected signs. However, it may be imperative to discuss some of the limitations of this exercise right in the beginning. It may be noted that there is a discrepancy between the time reference of the variables used and the phenomenon to be explained. Mortality and fertility, which are life-cycle phenomena may not be adequately explained by the regression exercise based on the cross-sectional nature of the data. In an exercise to avoid multicollinearity among the explanatory variables, a correlation matrix was produced. The correlation coefficients of all the variables used in this exercise were not found to be high enough to produce any collinearity problem. However, since mortality and fertility along with these variables are jointly determined, the problem of simultaneity cannot be absolutely ruled out. 
Table 1

Estimated Regression Equations for the Determination of Fertility Behaviour Dependent Variable "CEB"

\begin{tabular}{|c|c|c|c|c|}
\hline $\begin{array}{l}\text { Explanatory } \\
\text { Variables }\end{array}$ & $\begin{array}{c}\text { Equation } 1 \\
\text { (All Women) }\end{array}$ & $\begin{array}{l}\text { Equation } 2 \\
\text { (Women } \\
\text { Age }<25 \text { ) }\end{array}$ & $\begin{array}{l}\text { Equation } 3 \\
\text { (Women } \\
\text { Age 25-34) }\end{array}$ & $\begin{array}{l}\text { Equation } 4 \\
\text { (Women } \\
\text { Age }>34 \text { ) }\end{array}$ \\
\hline Constant & .2374 & -.4421 & .2469 & 1.0888 \\
\hline \multirow[t]{2}{*}{ Age } & $.8548 * * *$ & $.6087^{* * *}$ & $.4813^{* * *}$ & $.4312^{* * *}$ \\
\hline & $(90.65)$ & $(25.23)$ & $(32.33)$ & $(17.25)$ \\
\hline \multirow[t]{2}{*}{ Age at Marriage } & $-.4461^{* * *}$ & $-.6512^{* * *}$ & $-.6029 * * *$ & $-.4895 * * *$ \\
\hline & (47.39) & $(25.77)$ & (38.98) & $(19.36)$ \\
\hline Breastfeeding & $-0.0664^{* * *}$ & $-.1787^{* * *}$ & $-.0733^{* * *}$ & $-.0905^{* * *}$ \\
\hline (Av. Duration & $(6.40)$ & $(6.98)$ & $(4.20)$ & $(2.91)$ \\
\hline \multicolumn{5}{|l|}{ >12 Months) } \\
\hline Breastfeeding & $.0382^{* * *}$ & $.0908^{* * *}$ & $.03219^{* *}$ & $.0527^{* *}$ \\
\hline (Av. Duration & (3.72) & (3.55) & $(1.86)$ & $(1.68)$ \\
\hline \multicolumn{5}{|l|}{ 6-12 Months) } \\
\hline Education (Women) & $-.0180^{* *}$ & .0113 & -.0047 & $-.0823^{* * *}$ \\
\hline (upto Primary) & (1.98) & $(0.50)$ & $(0.30)$ & $(3.23)$ \\
\hline Education (Women) & $-.0675^{* * *}$ & $-.0518^{* *}$ & $-.0602^{* * *}$ & $-.1636^{* * *}$ \\
\hline (beyond Primary) & $(6.29)$ & $(1.97)$ & $(3.16)$ & $(5.59)$ \\
\hline Education (Husband) & -.0091 & $.03259^{*}$ & .0154 & .0037 \\
\hline (upto Primary) & $(0.99)$ & $(1.39)$ & $(.97)$ & $(.15)$ \\
\hline Education (Husband) & .0008 & .0141 & -.0085 & .0172 \\
\hline (beyond Primary) & $(.08)$ & $(0.54)$ & $(0.47)$ & $(.59)$ \\
\hline \multirow[t]{2}{*}{ Urbanisation } & $-.0458^{* * * *}$ & $-.0700^{* * * *}$ & $-.0447^{* * *}$ & $-.0790^{* * * *}$ \\
\hline & $(4.89)$ & $(2.98)$ & (2.78) & $(2.97)$ \\
\hline \multirow[t]{2}{*}{ Sex Ratio } & $.0165^{* *}$ & 0.0205 & $.0199^{*}$ & .0177 \\
\hline & (1.93) & $(0.94)$ & $(1.37)$ & $(0.72)$ \\
\hline Work Status & $-.0176^{* *}$ & $-.0289 *$ & $-.0391^{* * *}$ & .0052 \\
\hline (After Marriage) & (2.04) & $(1.32)$ & $(2.65)$ & $(.21)$ \\
\hline \multirow[t]{2}{*}{ Ever Users } & $.0763^{* * *}$ & $.0922 * * *$ & $.0905^{* * *}$ & $.1176^{* * *}$ \\
\hline & $(8.01)$ & $(3.91)$ & $(5.47)$ & $(4.43)$ \\
\hline \multirow[t]{2}{*}{ Immunisation } & .0043 & $.0472^{* *}$ & .0144 & -.0273 \\
\hline & $(.47)$ & (2.04) & $(0.92)$ & $(1.08)$ \\
\hline \multirow[t]{2}{*}{ Durable's Score } & $-.0131^{*}$ & 0.0072 & $-.0242^{*}$ & -.0254 \\
\hline & (1.41) & $(.32)$ & $(1.50)$ & $(.95)^{\circ}$ \\
\hline $\mathrm{R}^{-2}$ & .71 & .55 & .57 & .42 \\
\hline $\mathbf{F}$ & 696.76 & 85.63 & 191.81 & 52.55 \\
\hline Average & 4.37 & 2.02 & 4.20 & 7.00 \\
\hline S.D. & 2.71 & 1.20 & 2.09 & 2.60 \\
\hline $\mathbf{N}$ & 4019 & 972 & 2035 & 1012 \\
\hline $\begin{aligned} \text { Note: } & \text { t-statistios ar } \\
\text { *** Significant a } & \text { - Significant } \\
& * \text { Significant }\end{aligned}$ & $\begin{array}{l}\text { in parentheses. } \\
\text { ent level. } \\
\text { ent level. } \\
\text { cent level. }\end{array}$ & . & & \\
\hline
\end{tabular}


Table 2

Estimated Regression Equations for the Determination of Mortality Dependent Variable "Children Dead"

\begin{tabular}{|c|c|c|c|c|}
\hline $\begin{array}{l}\text { Explanatory } \\
\text { Variables }\end{array}$ & $\begin{array}{c}\text { Equation } 1 \\
\text { (All Women) }\end{array}$ & $\begin{array}{l}\text { Equation } 2 \\
\text { (Women } \\
\text { Age }<25 \text { ) }\end{array}$ & $\begin{array}{c}\text { Equation } 3 \\
\text { (Women } \\
\text { Age 25-34) }\end{array}$ & $\begin{array}{l}\text { Equation } 4 \\
\text { (Women } \\
\text { Age> 34) }\end{array}$ \\
\hline Constant & .5770 & .3688 & .4595 & .3082 \\
\hline \multirow[t]{2}{*}{ Age } & $.3241^{* * *}$ & $.2299^{* * * *}$ & $.1481^{* * *}$ & $.1519^{* * *}$ \\
\hline & $(20.34)$ & $(6.91)$ & $(6.89)$ & $(4.90)$ \\
\hline \multirow[t]{2}{*}{ Age at Marriage } & $-.2264^{* * *}$ & $-.2360^{* * *}$ & $-.2105^{* * *}$ & $-.2360^{* * *}$ \\
\hline & $(14.10)$ & $(6.89)$ & $\begin{array}{l}(9.40) \\
-0667^{* * *}\end{array}$ & $\begin{array}{l}(7.54) \\
-0534^{* * *}\end{array}$ \\
\hline Ever Breastfeeding & $\begin{array}{l}-.0697^{* * *} \\
(4.72)\end{array}$ & $\begin{array}{l}-.1693^{* * *} \\
(5.48)\end{array}$ & $(3.11)$ & $(1.77)$ \\
\hline Education (Women) & -.0157 & -.0203 & -.0265 & .0052 \\
\hline (upto Primary) & $(1.01)$ & $(0.63)$ & (1.17) & $(0.16)$ \\
\hline Education (Women) & $-.0315 * *$ & $-.0520^{*}$ & $-.0355^{*}$ & $-.0480^{*}$ \\
\hline (beyond Primary) & $(1.72)$ & $(1.40)$ & $(1.28)$ & $(1.33)$ \\
\hline Education (Husband) & .0123 & .0229 & $.0293^{*}$ & -.0087 \\
\hline (upto Primary) & $(.78)$ & $(.69)$ & $(.27)$ & $(.27)$ \\
\hline Education (Husband) & $-.0435 * * *$ & -.0037 & -.0309 & $-.0819^{* *}$ \\
\hline (beyond Primary) & $(2.41)$ & $(.10)$ & $(1.16)$ & $(2.27)$ \\
\hline \multirow[t]{2}{*}{ Urbanisation } & -.0002 & -.0339 & -.0104 & -.0248 \\
\hline & $(.01)$ & $(1.02)$ & $(.44)$ & $(.75)$ \\
\hline \multirow[t]{2}{*}{ Sex Ratio } & .0091 & .0173 & .0162 & -.0034 \\
\hline & $(.62)$ & $(.56)$ & $(.76)$ & $(0.11)$ \\
\hline Work Status & $.0369^{* * *}$ & -.0243 & .0256 & $.0806^{* * *}$ \\
\hline (After Marriage) & $(2.50)$ & $(.78)$ & $(1.19)$ & $(2.66)$ \\
\hline \multirow[t]{2}{*}{ Ever Users } & -.0025 & .0095 & $-.0376^{*}$ & $.0520 *$ \\
\hline & $(.15)$ & $(.29)$ & $(1.56)$ & $(1.58)$ \\
\hline \multirow[t]{2}{*}{ Immunisation } & $.0361^{* * *}$ & $-.0728^{* *}$ & $-.0355^{*}$ & -.0358 \\
\hline & $(2.34)$ & $(2.25)$ & $(1.57)$ & $(1.15)$ \\
\hline \multirow[t]{2}{*}{ Durable's Score } & $-.0214^{*}$ & -.0301 & -.0293 & -.0007 \\
\hline & $(1.34)$ & $(.93)$ & $(1.25)$ & $(.02)$ \\
\hline $\mathbf{R}^{-2}$ & .14 & .10 & .09 & .10 \\
\hline F & 51.78 & 9.10 & 15.81 & 9.61 \\
\hline Average & 0.51 & 0.22 & .47 & 0.86 \\
\hline S.D. & .97 & 0.54 & .89 & 1.27 \\
\hline $\mathrm{N}$ & 4019 & 972 & 2035 & 1012 \\
\hline
\end{tabular}

Note: $\quad$ t-statistics are given in parenthesis.

*** Significant at 1 percent level.

** Significant at 5 percent level.

* Significant at 10 percent level.

Age

As expected, age of women and mortality and fertility behaviour are found to be positive and significantly associated. The magnitude of the coefficient is also substantially high especially for the fertility equations. Across the age cohorts, the magnitude of the coefficient decreases as the age of the women increases. In our 
society, not only is the female age at marriage and contraceptive prevalence low but social values also compel a woman to produce children at an early age with short birth intervals. Thus, a decreasing magnitude of the coefficient across the age cohorts is an expected outcome.

\section{Age at Marriage}

Age at marriage is significantly and inversely associated to both fertility and mortality. However, the magnitude of the coefficient is smaller for mortality as compared to the fertility equations. A number of earlier studies using Pakistani data have demonstrated a strong negative effect of age at marriage on fertility and mortality [Karim (1980); Sathar (1985)]. Using Bongaarts model, the World Bank (1989) have estimated a reduction of about 4 children due to the increased age at marriage in Pakistan. In view of these findings, a substantial increase in the legal age at marriage in Pakistan may lead to an accelerated demographic transition.

\section{Contraceptive Use}

A significant positive association between contraceptive use and fertility is found. Two earlier studies based on Pakistani data arrived at similar results [Detray (1976); Irfan and Farooq (n.d.)]. It is argued that in countries like Pakistan where the contraceptive prevalence rate is low, it is the high parity women who engage in contraceptive practice [Shah and Ali, (1992)]. However, in Pakistan where family planning is still considered a taboo, under-reporting of its use cannot be ruled out.

Overall, the contraceptive use and number of children dead are found to be positively related. However, this relationship becomes negative and statistically significant in the case of women age 35 and above. In Pakistan, where the overall use rate is low (14 percent), a large proportion of the women who use contraceptives, are above 35 years of age. Such women are relatively frequent visitors to a health clinic or a family planning centre (both these places generally provide health as well as family planning services) and thus gain better access to health-care facilities in case of sickness of their children.

\section{Female Labour Force Participation}

Unlike many previous studies which did not yield a significant association between the work participation of women and fertility or mortality in Pakistan [Irfan and Farooq (n.d.); Casterline (1984)], this study, based on PDHS data, produced significant association between these variables. The difference between this study and the previous ones lies in the fact that the formor were based on the 'ever worked' or 'currently working' status of women whereas in this study we have taken into consideration the woman's work status only after marriage which may be more relevant while considering both mortality and fertility behaviour.

Overall, female labour force participation emerged as significantly associated with both fertility and mortality, producing an expected inverse relationship with 
fertility and a positive relationship with mortality. In Pakistan, only a few of the women in the labour force are in white collar jobs. The majority enter into menial jobs as maids, sweepresses or in the garment factories as workers. Such working women devote less time to the rearing of their children and thus exposing them to a greater risk to sickness. The income earned by doing such jobs is also too little to upgrade their economic status, which could enable them to provide better health care in case of sickness of their children.

The analysis pertaining to various age cohorts indicates that the relationship of female work participation with both fertility and mortality is not linear. However, the relationship turns out to be statistically insignificant.

\section{Urbanisation}

It is argued that urbanisation facilitates the demographic transition. Duncan and Reiss (1956) observed that urban industrial living brings social change leading to a reduction in fertility. Better health facilities in the urban areas increases the probability of survival. The urbanisation variable is introduced in the regression equation in order to test the validity of the argument in the Pakistani environment.

Urbanisation emerges as a highly significant variable affecting fertility at the 99 percent confidence interval. The inverse relationship is also in an expected direction. However, urbanisation does not yield a significant effect on 'children's mortality'.

\section{Sex Ratio}

Similar to many societies in the world, sons are valued in the Pakistani society due to various reasons. A study based on 1979-80 Pakistani data indicated marked differences in the demand for additional children among those who had at least one son than those who did not have a son [Ali (1989)].

In our analysis the sex ratio emerged as statistically significant only in case of Equation 1 and Equation 3 of Table 1 indicating an increase in the number of children with an increase in the female children in a family. However, the sex ratio did not yield a significant effect on 'children dead' suggesting that the deaths of children are not significantly more in the case of families with more girls. In other words, preferential treatment for sons especially when the children are in need of health care, does not explicitly hold true.

\section{Durable's Score}

The durable's score used as a proxy for the standard of living in the regression equations emerged as statistically significant and yielded an inverse effect on both fertility and mortality (see Eq. 1 of Table 1 and Table 2). However, across age cohorts the effect of the durable's score by and large loses its statistical significance except in the case of Equation 2, Table 1. 


\section{Husband's and Wife's Education}

Pakistan is considered a male dominated society where most of the decisions particularly of vital importance are taken by the male member of the household. Many previous studies have indicated husband's objection as one of the major reasons for not using family planning methods [Population Planning Council of Pakistan PFS (1976); Government of Pakistan (1986); Shah and Ali (1992)]. In another study, using Pakistani data, Sirageldin et al. (1976) have observed that a latent demand for contraceptive practice may have existed among women, but constraints such as husbands approval prevented them from actually converting it into effective demand.

In view of the situation, husband's education is considered to be an important determinant of mortality and fertility behaviour. However, the regression results show that husband's education did not emerge as strong as wife's education in determining fertility behaviour (see Table 1). Across the age cohorts women's education yielded a stronger effect for age cohort 35 and above than younger cohorts. This is true for both categories of women who have primary and those who have beyond primary education. This outcome re-emphasises the importance of imparting education among females in order to control fertility.

On the other hand, husbands who were educated beyond the primary level yielded a stronger and an expected negative effect on the mortality of children as compared to women with the same level of education. In terms of statistical significance, this relationship emerged stronger for younger women than those in the older age brackets.

\section{Breastfeeding Practice}

Interestingly, women who did not breastfeed at all and where the average duration of breastfeeding is less then six months bear significantly more children than those who breastfed between 6 to 12 months. Using PLM data, Irfan and Farooq (n.d.) also found a similar trend.

However; a longer duration of breastfeeding (more than 12 months) yielded an expected negative association with the 'children everborn'. Likewise, breastfeeding also exhibited a significant and negative effect on the number of children dead.

\section{Immunisation}

Overall, immunisation of children yields a positive but insignificant effect on the number of children everborn. The effect becomes significant only in case of equation pertaining to women age less than 25. As a matter of fact, the Expanded Programme on Immunisation (EPI) in Pakistan has achieved great successes in recent years and since all newborn babies are the target population for this programme, a positive association between immunisation and fertility is an expected outcome. 
On the other hand, immunisation yielded an inverse and statistically significant effect on "children dead" with a confidence interval at 99 percent. Across the age cohorts, the relationship remained statistically significant. Nevertheless, the largest coefficient is estimated for younger women than the older ones.

\section{SUMMARY AND CONCLUSION}

Mortality and fertility-the two being the important components of demographic transition are studied in order to find the commonalties and similarities in the determinants of the two. The results indicate that some of their traditional and nontraditional determinants were the same, although the magnitude of variation brought about by these determinants and the significance level varied.

The age, age at marriage and education of women beyond the primary level emerged as important determinants for both mortality and fertility at the aggregate and subaggregate level. Moreover, everbreastfed yielded a significant negative effect on mortality whereas, breastfeeding beyond 12 months exhibited a significant negative effect on fertility.

Overall, variables such as urbanisation, sex ratio, work status of women, ever users and durable's score emerged statistically significant, affecting fertility behaviour whereas, the education of husbands beyond the primary level, work status of women, immunisation of children and durable's score exhibited a significant effect on the mortality of children.

In developing countries such as Sri Lank, Indonesia and Thailand, the increased level of female education seems to have played a greater role bringing a change in the attitudes of women towards small family size norms. Universal female education upto at least the secondary level will raise the age at marriageanother important determinant of fertility and mortality and will bring about a positive change in the attitudes which, in turn, will facilitate the demographic transition to progress at a faster pace in Pakistan than otherwise expected.

\section{REFERENCES}

Ali, S. Mubashir (1989) Does Son Preference Matter? Journal of Bio-Social Science 21:4.

Casterline, John (1984) Fertility Differentials. In Iqbal Alam and Betzy Dinesen (eds) Fertility in Pakistan. Voorburg, Netherlands: International Statistical Institute.

DeTray, Dennis (1976) On the Micro-Economics of Family Behaviour in Developing Societies. (Mimeographed.)

Duncan, Otis D., and Albert J. Reiss (1956). Social Characteristics of Urban and Rural Communities 1950. New York: John Wiley and Sons.

Irfan, Mohammad, and G. M. Farooq (n.d.) An Investigation of Household Reproductive Behaviour in Pakistan: Islamabad: Pakistan Institute of Development Economics. (PLM Report No. 4.) 
Karim, Mehtab (1980) Nuptiality in Pakistan: Trends and Determinants. World Fertility Survey Conference Background Paper No.2.

Nasra, M. Shah, and S. Mubashir Ali (1992) Knowledge and Use of Family Planning (Chapter 5) in Pakistan Demographic and Health Survey 1990-1991. National Institute of Population Studies, Islamabad/IRD/Macro International Inc., Columbia.

Pakistan, Government of (1986) Pakistan Contraceptive Prevalence Survey 198485. Islamabad: Population Welfare Division.

Population Planning Council of Pakistan (1976) Pakistan Fertility Survey: First Report. Voorburg, Netherlands: International Statistical Institute.

Sathar, Zeba A. (1985) Infant and Child Mortality in Pakistan-Some Trends and Differentials. Journal of Bio-Social Science 17:3.

Sirageldin, I, D. Norris and J. Gilbert Hardee (1976) Family Planning in Pakistan: An Analysis of Some Factors Constraining Use. Studies in Family Planning 7:5 World Bank (1989) Rapid Population Growth in Pakistan: Concerns and Consequence. Washington, D. C.: The World Bank. 